\title{
Flavor Perception in Human Infants: Development and Functional Significance
}

\author{
Gary K. Beauchamp Julie A. Mennella \\ Monell Chemical Senses Center, Philadelphia, Pa., USA
}

\section{Key Words}

Taste $\cdot$ Smell $\cdot$ Flavor $\cdot$ Infant $\cdot$ Child $\cdot$ Food $\cdot$ Imprinting

\begin{abstract}
Background: Foods people consume impact on their health in many ways. In particular, excess intake of salty, sweet and fatty foods and inadequate intake of fruits and vegetables have been related to many diseases including diabetes, hypertension, cardiovascular disease and some cancers. The flavor of a food determines its acceptability and modulates intake. It is thus critical to understand the factors that influence flavor preferences in humans. Aim: To outline several of the important factors that shape flavor preferences in humans. Methods: We review a series of studies, mainly from our laboratories, on the important role of early experiences with flavors on subsequent flavor preference and food intake. Results and Conclusions: Some taste preferences and aversions (e.g. liking for sweet, salty and umami; disliking for bitter) are innately organized, although early experiences can modify their expression. In utero events may impact on later taste and flavor preferences and modulate intake of nutrients. Both before and after birth, humans are exposed to a bewildering variety of flavors that influence subsequent liking and choice. Fetuses are exposed to flavors in amniotic fluid modulating preferences later in life and flavor learning continues after birth. Experience with flavors that are bitter, sour or have umami characteristics, as well as volatile flavors
\end{abstract}

\section{KARGER}

(C) 2011 S. Karger AG, Basel

Fax +4161306 1234

E-Mail karger@karger.ch

www.karger.com
Accessible online at: www.karger.com/dig such as carrot and garlic, occurs through flavorings in breast milk, infant formula and early foods. These early experiences mold long-term food and flavor preferences which can impact upon later health.

Copyright $\odot 2011$ S. Karger AG, Basel

\section{Flavor Perception}

The flavor of a food or beverage is defined here as the perceptual combination of three anatomically distinct sensory systems, namely smell (cranial nerve 1), oral chemical somatosensory stimulation (cranial nerve 5) and taste (cranial nerves 7, 9, and 10). Thus we do not consider visual or auditory stimuli as contributing to flavor, although these sensory systems are certainly involved in food identification, choice and appreciation.

A remarkable aspect of flavor perception is that, although the sensory systems that underlie it are completely anatomically separate, the sensory impression is unitary. That is, we do not typically analyze the flavor of a carbonate beverage, for example, into its sweetness, the degree to which it tingles, and its fruitiness; instead we perceive a carbonated beverage as a single impression. How the brain accomplishes this melding of the senses into a single percept is the focus of much current research using various methods but particularly, in humans, functional magnetic resonance imaging.

Gary K. Beauchamp

Monell Chemical Senses Center

3500 Market Street, Philadelphia, PA 19104 (USA)

Tel. +1 267519 4710, Fax +1 2158982084

E-Mail beauchamp@monell.org 


\section{Importance of Flavor Perception}

It is generally believed that the senses of vision and hearing are the most important, at least for humans, because it is so devastating to lose them. In contrast, the chemical senses of flavor are considered of secondary importance: their loss, while unpleasant, is not as serious. This view is debatable on two grounds. First, most people do not realize how difficult it would be to live without any flavor perception because it is extremely rare to lose all three sensory systems simultaneously. Indeed, it is even quite rare to lose the sense of taste (ability to detect sweet, sour, salty, bitter and umami), but when it does occur, for example following radiation therapy for head and neck cancer, eating and nutrition is often severely compromised [1]. Second, while loss of the flavor senses may not be as disruptive as loss of vision and hearing, the behaviors that they mediate, particularly food choice and intake, are among the most important ones in terms of the health problems found in developed and developing societies. That is, a full understanding of flavor perception is central to preventing such diseases as hypertension, obesity, heart disease, diabetes and some cancers. All of these diseases are strongly impacted by food choices which in turn are determined, in part, by how much we like (or dislike) the flavor of the food. Rather than being secondary senses, the chemical senses of flavor take a primary role when it comes to major issues of human health.

\section{Expanding Our Conception of Flavor and Taste}

Flavor is by definition a perceptual quality elicited by molecules associated with foods and beverages. During the past two decades, major advances have been made in our understanding of how these flavor molecules are recognized at the intersection between the mucus membranes of the oral and nasal cavities and the neural processes that send flavor messages to the brain. We now know much about olfactory receptor structure and function [2], the receptors for pungent chemicals such as capsaicin, carbonation and the cooling of menthol [3], and taste receptor structure and function.

We focus here on one of these sensory systems, the sense of taste. For hundreds of years, investigators have speculated on the nature of the receptors for taste compounds, but it has not been until the last 10 years or so that definitive studies of their molecular nature have been published [4]. We now know that sweet stimuli are primarily or exclusively recognized by a dimer consisting of two closely related 7-transmembrane receptors (T1R3 and T1R2) that together form a venus flytrap structure atop taste receptor cells of taste buds on the tongue and the palate. Umami taste (the taste characteristic of the sodium salt of glutamic acid - MSG - in humans and apparently a more general amino acid receptor in many other species) is also recognized by a dimer (T1R 3 and T1R1), but other glutamate receptors have also been implicated. Bitter taste is recognized by a family of about 25 7-transmembrane receptors (the T2Rs), although we are still unsure as to the sensitivities of each receptor to specific bitter compounds as well as whether there may be other mechanisms of detecting bitter compounds. Still something of a puzzle is the nature of sour and salty receptors. It is thought that sour taste is mediated by a channel protein and a number of candidate receptors have been suggested. Salt taste has long been thought to be detected by an epithelial sodium channel (an ENaC), and recently this has been strongly supported by studies demonstrating in mouse models that if the $\mathrm{ENaC}$ is disrupted, salt taste response is altered $[5,6]$. However, these mice with the disrupted $\mathrm{ENaC}$ retain substantial responsiveness to sodium and other salts demonstrating that there is/are additional mechanisms for detecting salt that remain to be defined. The taste system may also be responsive to other classes of compounds (e.g. calcium salts, fatty acids), but less is known about the underlying mechanisms for detecting these nutrients [4].

The identification of taste receptors for sweet, umami and bitter compounds about a decade ago set off an explosion of studies to characterize them, to explore the relationships between structure and function, to investigate their variation within and between species and to evaluate their functional characteristics. It also set in place a search to determine whether they might be expressed in tissues outside the mouth. Surprisingly - or perhaps in hindsight not so surprising - so-called taste receptors were identified in the gut, the pancreas and the brain $[7,8]$.

Understanding the functional significance of these receptors in these non-oral organs is now an extremely active area of research and it is expected that they may play a significant role in nutrient recognition and regulation $[7,8]$. Had investigators first identified these receptors in the gut, they may well have been labeled gut chemosensory receptors. In this case there would have been surprise to discover that they are also found in the mouth! One can now consider the ingestive and digestive tube, from the mouth through the stomach and intestine, to be a single super organ. This super organ first recognizes 
and discriminates among nutrients consciously by oral and nasal receptors when decisions to accept or reject are made. Next, once nutrients pass the mouth and enter the gut, these same receptors, as well as others, no longer signal the presence of nutrients consciously but instead respond by producing local hormonal signals or by sending messages through the vagus nerve to the unconscious parts of the brain that are important for nutrient recognition and utilization. These conscious and unconscious signals are orchestrated so that food can be efficiently recognized and processed and that non-foods (e.g. bitter toxic compounds) are avoided or detoxified.

\section{Origin of Flavor Preferences}

Flavor perception and preferences guide food selection, but what determines flavor preferences? We have been investigating this question in a program of research that has focused on the interacting role of genetic and experiential influences in the human fetus, the infant and the child. In this section, we briefly describe some of our findings. This work has been more thoroughly reviewed recently elsewhere [9] from which this summary is taken.

Liking for taste stimuli is generally strongly influenced by inborn (innate) factors [10]. For example, foods that are sweet are innately preferred by most or all herbivores and omnivores, presumably since sweetness reflects the presence of caloric sugars in plants. Infants and children have higher preferences than adults and these preferences can be modified by experience [for review, see 11]. For umami, an innate component to liking is also likely [11]. Bitter taste signals the presence of potentially toxic compounds and hence substances that are bitter are generally disliked and avoided [12]. That many of the bitter foods that people like most (e.g. coffee, tea, beer) have pharmacological properties helps explain their desirability and the fact that people need to learn to like them. Nevertheless, with experience even bitter vegetables can come to be liked $[13,14]$, although whether the bitterness of these is actually liked or whether the other flavor characteristics are sufficient to overcome the dislike of bitterness is not known.

A sensitivity to and preference for salty tasting substances (almost the only one being $\mathrm{NaCl}$ ) also appears to have an innate component that develops at around 4 months of age. By 2 years of age, children's preferences for salty foods are even greater than they are for adults $[1,15]$. Along with proposed innate factors, prenatal developmental events modify the infant's and child's preferences for salty tastes. Severe maternal emesis can have an enduring influence on response of offspring to salty taste [16-18]. Similarly, we have shown [19] that several behavioral measures related to salty taste preference are inversely related to birth weight over the first 4 years of life. Recent unpublished studies from our laboratories suggest that early experiences may profoundly modify the degree of salt liking in children. If verified, these observations are significant since it is generally accepted that excess salt intake can lead to or exacerbate hypertension. One set of factors predisposing children and adults to high salt intake may be the heightened preferences that are caused by in utero and early postnatal experiences.

\section{Flavor Learning: Prenatal Life}

Preferences for flavor compounds detected by the sense of smell are generally more highly influenced than taste preferences by learning with learning early in life, even in utero, being particularly salient $[10,20]$. The sensory environment in which fetuses live, the amniotic sac, changes as a function of the food choices of the mother since these foods flavor amniotic fluid [21]. Experiences with such flavors lead to heightened preferences for these flavors shortly at birth $[22,23]$ and at weaning [24]. In an experimental study, infants whose mothers were randomly assigned to drink carrot juice during the last trimester of pregnancy enjoyed carrot-flavored cereals more than infants whose mothers did not drink carrot juice or eat carrots [24]. Thus, like other mammals, prenatal experiences with food flavors transmitted from the mother's diet to amniotic fluid lead to greater acceptance and enjoyment of these foods during weaning.

\section{Postnatal Flavor Learning via Infant Formula}

Flavor learning continues after birth as a consequence of exposure to commercial infant formulas and/or to breast milk. Studies of formula feeding allow us to precisely control sensory experiences of the infant, and through this research we have demonstrated there is a sensitive learning period in the first several months of life during which unpalatable flavors (to those not familiar with them) can be rendered palatable.

This body of research has randomized infants to feed either standard commercial cow milk formulas (CMF) or extensively protein hydrolysate formulas (PHF) since these formulas differ enormously in flavor. In particular, the flavor of PHF is extremely unpleasant to those unfamiliar with them, having a bitter and sour taste, and a nauseating smell and aftertaste, perhaps because many amino acids taste sour and bitter [25]. Infants less than 
3-4 months of age who have never been exposed to hydrolyzed casein (HC) formulas readily accept them and appear not to dislike them as determined both by their willingness to consume them and by the absence of characteristic facial responses of rejection when being fed them $[26,27]$. In marked contrast, infants over 5-6 months of age with no experience with $\mathrm{HC}$ formulas strongly dislike and reject them [26, 27]. However, infants tested at about this same age who have never been exposed to $\mathrm{HC}$ formulas during the first few months of life not only do not reject them but even appear to relish them [28].

A clinical trial to characterize the timing and duration of this sensitive period [28] demonstrated that 3 months of PHF exposure led to a similar acceptance as 1 month of exposure. Although these infants were more accepting than infants with no exposure, they were less accepting than infants with 7 months of exposure, thereby providing strong evidence for a dosing effect. The infant's age when flavor experiences began was also significant. Among infants exposed to PHF for 1 month, those who first fed PHF at 3.5 months rejected PHF relative to CMF on its first presentation more than infants exposed at younger ages, which provides evidence for a timing effect with younger infants being more willing to sample.

Although we have identified one sensitive period for the acceptance of PHF, one cannot assume there is only one sensitive period in flavor programming, any more than there is only one sensitive period for auditory learning [29] or visual learning [30]. The model system that we identified allows us to explore the ability to change behavior based on experiences during only one period. Like other senses, windows of plasticity in flavor learning may occur at different developmental periods. Moreover, they surely do not shut abruptly, and significant plasticity is retained as the child ages. Thus, learning of new flavor preferences can occur across the life span. What we argue here is that there is greater plasticity and more permanent effects of early compared with later flavor experiences.

But what exactly is learned during this early sensitive period? In one study we exploited the fact that although all brands of PHF share common flavor attributes and are all perceived as unpleasant by unexposed older children and adults, they each have unique flavor characteristics [25]. Infants were found to prefer the flavor of the brand of PHF on which they had been fed over an unfamiliar brand. In other words, flavor acceptance is quite specific to the flavors experienced. This suggests that during PHF exposure infants form a relatively precise flavor image which, when later matched, enhances intake and elicits pleasure.
Among infants tested prior to being introduced to table foods, experiences with flavors in formula impact on preferences for the taste qualities in food. Infants feeding PHF ate larger amounts of infant cereals that tasted savory, sour and bitter, and ate them at a faster rate than those fed milk-based formulas [14]. That they liked the savory- and bitter-tasting cereals is indicated by the fewer facial expressions of distaste displayed during feeding. When compared to CMF, and presumably breast milk $[31,32]$, PHF formulas have more pronounced savory, bitter and sour tastes and stronger odors [25]. Thus, infants who regularly feed PHF have more experiences early in life during sensitive periods with these taste and flavor qualities which impacts on later food choice.

The effects of formula-based flavor experiences are long-lived. Four- to 5-year-old children who were fed PHF during infancy exhibited more positive responses to foods and beverages characterized by sensory attributes associated with them (e.g. sour taste, aroma, chicken, broccoli) when compared with same-aged children without such experience $[33,34]$. These results are consistent with studies on children and adults with phenylketonuria (PKU). The dietary regimen to treat PKU consists of an unpalatable (to unexposed individuals) $\mathrm{HC}$ formula with phenylalanine removed. When given a choice, children and adolescents with PKU preferred their bad-tasting formula to that of the new formulation that was more palatable to naive children and adults [35]. In other words, the characteristic flavor of the formula experienced in early life is 'imprinted' and remains as a preference for a considerable time.

\section{Postnatal Flavor Learning via Human Milk}

We believe that the principles revealed in studies with controlled exposures to infant formulas apply directly to the natural breastfeeding situation. Human milk contains not only nutrients such as carbohydrates, proteins, vitamins and minerals, but also flavors which are derived from the foods, spices and beverages ingested or inhaled (e.g. tobacco) by the mother [20, 24, 36-39]. In this regard, the natural feeding experience of the breast-fed infants is characterized by a great variability of flavor experiences that depend directly on the dietary choices made by the mother. For example, when nursing mothers consume garlic, vanilla or many other flavors, their milk becomes recognizably flavored and these flavors are detected by the nursing infant. Thus breast-fed infants experience flavor compounds from the foods and beverages that the mother has chosen to consume, and these experiences influence the infants' subsequent liking and acceptance 
of these flavors in foods as has been reported for other mammals [40-42]. Breast milk may thus serve as a 'bridge' between the in utero experiences with flavors in amniotic fluid to those in solid foods at weaning and beyond. Breastfeeding (unlike formula feeding) provides the infant with the potential for a rich source of varying flavor experiences. Since the sweetness and textural properties of human milk, such as viscosity and mouth coating, also vary both between and within mothers [31, 32], breastfeeding provides an even richer variation in oral sensory stimulation.

How does this early sensory experience with flavors in breast milk impact on food choice? The study referred to earlier [24] on carrot flavor exposure in utero also included a group of breastfeeding infants whose mothers consumed carrot juice during the first 3 months of the infants' life. The exposure to flavors in breast milk enhanced the infants' responses to carrot flavor when they were tested at weaning to approximately the same degree as the in utero experience did. This demonstrates that there is redundancy in early flavor learning and that it extends from before birth into early infancy at least.

In a related study, breast-fed infants were more accepting of peaches than formula-fed infants, as determined by intake, rate of consumption and facial expressions. This enhanced acceptance of fruit was likely due to more exposure to fruit flavors since their mothers ate more fruits during lactation [13]. We suggest that breast-fed infants learn to prefer flavors associated with fruits and vegetables by experiencing these flavors in mothers' milk. This highlights the importance of a varied diet for both pregnant and lactating women. This variety of flavor ex- periences during early ontogeny may be the reason that, compared to formula-fed infants, breast-fed infants are less picky [43] and are more willing to try new foods [44]. Conscious efforts to increase vegetable and fruit consumption among pregnant and lactating women could be a potent strategy to enhance fruit and vegetable consumption of their children.

In summary, the flavor world of infants, particularly those that are breast-fed, is complex. Early experiences with flavor compounds carried in amniotic fluid and in breast milk modify later flavor and food preferences. These experiences interact with genetic differences in flavor perception $[45,46]$ and together genes and experience play a central role in establishing food likes and dislikes thereby impacting on the health and wellness of the infant, the child and the adult. An appreciation of the role of early experiences during sensitive periods in flavor learning and a greater understanding of the different means by which infants communicate their liking of tastes and flavors, will aid in our development of evidence-based strategies to facilitate healthy eating by everyone.

\section{Acknowledgement}

Preparation of the manuscript was supported in part by NIH Grant HD37119.

\section{Disclosure Statement}

No conflicts of interest exist.

\section{References}

1 Lees J: Incidence of weight loss in head and neck cancer patients on commencing radiotherapy treatment at a regional oncology centre. Eur J Cancer Care 1999;8:133-136.

- Touhara K: Progress in research and clinical practice concerning olfactory sensation importance of the olfactory mucus in the olfactory sense and signal transduction to the brain (in Japanese). Nippon Jibiinkoka Gakkai Kaiho 2008;111:475-480.

-3 Bautista DM, Jordt SE, Nikai T, Tsuruda PR, Read AJ, Poblete J, et al: TRPA1 mediates the inflammatory actions of environmental irritants and proalgesic agents. Cell 2006;124: $1269-1282$.

\footnotetext{
4 Bachmanov AA, Beauchamp GK: Taste receptor genes. Annu Rev Nutr 2007;27:389414.

-5 Chandrashekar J, Kuhn C, Oka Y, Yarmolinsky DA, Hummler E, Ryba NJ, Zucker CS: The cells and peripheral representation of sodium taste in mice. Nature 2010;464:297301.

6 Bosak NP, Inoue M, Nelson TM, Hummler E, Ishiwatari Y, Bachmanov AA: Epithelial sodium channel $(\mathrm{ENaC})$ is involved in reception of sodium taste; evidence from mice with a tissue-specific conditional targeted mutation of the $\mathrm{ENaC}$ gene. Abstract presented at the 2010 Annual Meeting of the Association for Chemoreception Sciences, Florida.
}

\footnotetext{
Margolskee RF, Dyer J, Kokrashvili Z, Salmon KS, Ilegems E, Daly K, et al: T1R3 and gustducin in gut sense sugars to regulate expression of $\mathrm{Na}^{+}$-glucose cotransporter 1 . Proc Natl Acad Sci USA 2007;104:1507515080.

8 Sclafani A: Sweet taste signaling in the gut. Proc Natl Acad Sci USA 2007;104:1488714888.

$\checkmark$ Beauchamp GK, Mennella JM: Early flavor learning and its impact on later feeding behavior. J Pediatr Gastroenterol Nutr 2009; 48:S25-S30.
}

Flavor Perception in Infants:

Development and Functional Significance
Digestion 2011;83(suppl 1):1-6 
10 Bartoshuk LM, Beauchamp GK: Chemical senses. Annu Rev Psychol 1994;45:419-449.

11 Cowart BJ, Beauchamp GK, Mennella JA: Development of taste and smell in the neonate; in Polin RA, Fox WW, Abman SH (eds): Fetal and Neonatal Physiology, ed 3. Philadelphia, Saunders, 2004, vol 2, pp 1819-1827.

12 Glendinning JI: Is the bitter rejection response always adaptive? Physiol Behav 1994; 56:1217-1227.

13 Forestell CA, Mennella JA: Early determinants of fruit and vegetable acceptance. Pediatrics 2007;120:1247-1254.

14 Mennella JA, Forestell CF, Morgan L, Beauchamp GK: Early milk feeding influences taste acceptance and liking during infancy. Am J Clin Nutr 2009;90:780S-788S.

15 Cowart BJ, Beauchamp GK: The importance of sensory context in young children's acceptance of salty tastes. Child Dev 1986;57: 1034-1039.

16 Crystal SR, Bernstein IL: Morning sickness: impact on offspring salt preference. Appetite 1995;25:231-240.

-17 Crystal SR, Bernstein IL: Infant salt preference and mother's morning sickness. Appetite 1998;30:297-307.

18 Leshem M: The ontogeny of salt hunger in the rat. Neurosci Biobehav Rev 1999;23:649659.

$>19$ Stein LJ, Cowart BJ, Beauchamp GK: Salty taste acceptance by infants and young children is related to birth weight: longitudinal analysis of infants within the normal birth weight range. Eur J Clin Nutr 2006;60:272279.

20 Mennella JA: The chemical senses and the development of flavor preferences in humans; in Hartmann PE, Hale T (eds): Textbook on Human Lactation. Amarillo, Hale Publishing, 2007, pp 403-414.

21 Mennella JA, Johnson A, Beauchamp GK: Garlic ingestion by pregnant women alters the odor of amniotic fluid. Chem Senses 1995;20:207-209.
22 Schaal B, Marlier L, Soussignan R: Human foetuses learn odours from their pregnant mother's diet. Chem Senses 2000;25:729737.

23 Hepper PG: Adaptive fetal learning: prenatal exposure to garlic affects postnatal preferences. Anim Behav 1988;36:935-936.

24 Mennella JA, Jagnow CP, Beauchamp GK: Prenatal and postnatal flavor learning by human infants. Pediatrics 2001;107:E88.

25 Mennella JA, Beauchamp GK: Understanding the origin of flavor preferences. Chem Senses 2005;30(suppl 1):i242-i243.

26 Mennella JA, Beauchamp GK: Developmental changes in the acceptance of protein hydrolysate formula. J Dev Behav Pediatr 1996 17:386-391.

27 Mennella JA, Beauchamp GK: Development and bad taste. Pediatr Allergy Asthma Immunol 1998;12:161-163.

28 Mennella JA, Griffin CE, Beauchamp GK Flavor programming during infancy. Pediatrics 2004;113:840-845.

29 Ruben RJ: A time frame of critical sensitive periods in language development. Acta Otolaryngol 1997;117:202-205.

30 Lewis TL, Maurer D: Multiple sensitive periods in human visual development: evidence from visually deprived children. Dev Psychobiol 2005;46:163-183.

31 Barker E: Sensory Evaluation of Human Milk (Dissertation). Manitoba, University of Manitoba, 1980

32 McDaniel MR: Off-Flavors in Human Milk. The Analysis and Control of Less Desirable Flavors in Foods and Beverages. New York, Academic Press, 1980, pp 267-291.

33 Liem DG, Mennella JA: Sweet and sour preferences during childhood: role of early experiences. Dev Psychobiol 2002;41:388-395.

34 Mennella JA, Beauchamp GK: Flavor experiences during formula feeding are related to preferences during childhood. Early Hum Dev 2002;68:71-82.
35 Owada M, Aoki K, Kitagawa T: Taste preferences and feeding behaviour in children with phenylketonuria on a semisynthetic diet. Eur J Pediatr 2000;159:846-850.

36 Mennella JA, Beauchamp GK: Maternal diet alters the sensory qualities of human milk and the nursling's behavior. Pediatrics 1991; 88:737-744.

37 Mennella JA, Beauchamp GK: Smoking and the flavor of breast milk. N Engl J Med 1998; 339:1559-1560.

38 Mennella JA, Beauchamp GK: The transfer of alcohol to human milk. Effects on flavor and the infant's behavior. N Engl J Med 1991; 325:981-985.

39 Mennella JA, Beauchamp GK: The human infants' responses to vanilla flavors in human milk and formula. Infant Behav Dev 1996;19:13-19.

- 40 Bilko A, Altbacker V, Hudson R: Transmission of food preference in the rabbit: the means of information transfer. Physiol Behav 1994;56:907-912.

41 Galef BG Jr, Sherry DF: Mother's milk: a medium for transmission of cues reflecting the flavor of mother's diet. J Comp Physiol Psychol 1973;83:374-378.

42 Nolte DL, Provenza FD: Food preferences in lambs after exposure to flavors in milk. Appl Anim Behav Sci 1991;32:381-389.

43 Galloway AT, Lee Y, Birch LL: Predictors and consequences of food neophobia and pickiness in young girls. J Am Diet Assoc 2003; 103:692-698

44 Sullivan SA, Birch LL: Infant dietary experience and acceptance of solid foods. Pediatrics 1994;93:271-277.

45 Cooke LJ, Wardle J, Gibson EL, Sapochnik M, Sheiham A, Lawson M: Demographic, familial and trait predictors of fruit and vegetable consumption by pre-school children. Public Health Nutr 2004;7:295-302.

46 Mennella JA, Pepino MY, Reed DR: Genetic and environmental determinants of bitter perception and sweet preferences. Pediatrics 2005;115:e216-e222. 